\title{
Writing across the academic languages: introduction
}

\author{
Elaine R. Silliman ${ }^{1} \cdot$ Ruth Huntley Bahr ${ }^{1}$ - Louise C. Wilkinson ${ }^{2}$
}

Published online: 12 December 2019

(c) Springer Nature B.V. 2019

Writing-to-learn is essential for achieving a broad array of educational, vocational, and personal purposes because it is a major tool for acquiring new knowledge and levels of self-reflection (Silva \& Limongi, 2019). Moreover, writing-to-learn is a communication skill whose ongoing refinement extends throughout adolescence, if not the life span (Berman, 2007, 2008). Worldwide, many students do not attain competence in writing-to-learn during their schooling. This finding is attributed to the overall quality of and experiences with writing instruction across the grades (Dockrell, Marshall, \& Wyse, 2016; Graham, 2019; Nelson \& Watkins, 2019), and the likelihood that writing-to-learn requires the multifaceted cognitive ability to "take sole responsibility for the construction of thematically coherent monologic text" (Christie \& Derewianka, 2008, p. 20). In the United States, the last national assessment of student writing abilities at grades 8 and 12 (U.S. Department of Education, Institute of Education Sciences, 2011) indicated that only $24 \%$ of students demonstrated proficiency in their ability to construct expository texts that required persuasion and explanation. Approximately $20.5 \%$ performed below a basic level of competence. ${ }^{1}$ The failure to attain writing proficiency by the end of secondary schooling has critical ramifications not only for student success in a new global order but also for the ways in which we conceptualize and implement writing practices.

Despite its central role in the implementation of national standards in education, such as the U.S. Common Core State Standards (www.corestandards.org), writing-to-learn has received minimal attention in the academic language literature. In contrast, prior academic language studies primarily focused on either reading comprehension or vocabulary. In addition, beyond vocabulary, the academic language production of students with significant language learning difficulties, including oral language, reading, and writing, has not been systematically investigated (Silliman \& Wilkinson, 2015). To remedy these situations, a special section of this issue is dedicated to articles on writing in the academic

\footnotetext{
1 Results from the 2017 writing assessment will not be published until sometime in 2020 .
}

Elaine R. Silliman

silliman@usf.edu

1 University of South Florida, Tampa, USA

2 Syracuse University, Syracuse, USA 
language registers, the medium of expression through which academic concepts are translated into the written discourse of the disciplines. As a preface, consider this excerpt from an account of a science experiment, specifically a chemistry lab report, written by a 15-year-old female who is a high school sophomore:

In this lab, I predicted that it [the hydrogen lab] would have similar results to the oxygen lab because the procedures were the same. The importance of this lab is for the students to be familiarized with meta-acid reaction that produces hydrogen gas, water displacement, and several properties of hydrogen gas (Silliman, Wilkinson, \& Brea-Spahn, 2018, p. 122).

This brief passage encapsulates the special section focus, as the manner of writing is consistent with the language of schooling or an academic language register. Registers combine cognitive, linguistic, and social dimensions as these interact continuously with the situational context, which filters "the choice of linguistic features from the language system" (Neumann, 2016, p. 36). This means that, at the broadest level, registers represent the ways in which linguistic and discourse resources vary in keeping with how a speaker-writer in a particular context interprets the genre to be produced (Bar-Ilan \& Berman, 2007); hence context and genre are interwoven (Christie \& Derewianka, 2008).

The two general genre categories, narrative and expository, are not unitary but have multiple variations that can overlap (Wallis, Richards, Boord, Abbott, \& Berninger, 2017). The genres differ in their communicative goals, content, textual organization, and distribution of linguistic features, and these register distinctions seem to be similar across languages (see Bar-Ilan and Berman, 2007; Biber, 2016 for further discussion on debates about the uniqueness of academic language, see Fang \& Park in this special section). Narrative discourse, whether fictional or non-fictional, expresses dynamic events typically from a more subjective and emotive point of view. In contrast, expository discourse tends towards the abstract and impersonal in the expression of ideas and related information, favors academic or more literate language registers, and is often associated with disciplinary content, like the chemistry lab report. As the brief sample from the lab report illuminates, the writer seems on her way to using writing-to-learn to construct a chemistry register. Therefore, command of academic language registers is not only critical for processing various types of disciplinary content (Cummins, 2014) but also for assuming a productive academic identity (Zwiers \& Crawford, 2011).

The segment from the chemistry lab report also illustrates why the concept of a unified academic language is likely misleading. The disciplines have their own linguistic and discourse repertoires; that is, each has their own way of facilitating how students are expected to write, read, listen, speak, and reason (Biber \& Gray, 2016; Fang, Scheppegrell, \& Moore, 2014). Hence, the notion of academic languages is preferred because it encompasses the linguistic-discourse variations inherent to the broad diversity of disciplinary content, from the languages of science to the languages of history and mathematics to the languages of the humanities and literature, among other disciplines. As Biber and Gray (2016) note, the 
discourse styles of academic language writing are often misunderstood as the intentional obscuring of meaning just to show "how smart" one is at saying nothing for distant readers who are frequently non-specialists. Rather than engage in deliberate camouflage and depending on the discipline, good academic writing should vary how the multiple levels of language pattern for particular audiences the expression of general academic language versus specialized language registers (or sub-registers).

\section{Multiple levels of language and academic language registers}

It may be intuitive that language systems comprise speaking, listening, reading, and writing. Less intuitive is that each of these systems (Abbott, Berninger, \& Fayol, 2010; Berninger, Abbott, \& Richards, 2015; Silliman \& Berninger, 2011; Silliman \& Wilkinson, 2015): (1) are multileveled (at the sub-word, word/multiword, phrase/ syntactic, and discourse/textual levels); (2) are dynamic and interconnected; and (3) interact with the infrastructures of "sensory, motor, social emotional, cognitive, and attention/executive functions in the brain" (James, Jao, \& Berninger, 2016, p. 116). Weaving the multidimensional strands of language into the proficient ability known as writing-to-learn can be challenging because of the variety of factors involved. These influences include home socialization practices; community, school, and peer interactions; cultural beliefs; and motivational factors (Silliman \& Wilkinson, 2015; Silliman, Wilkinson, \& Brea-Spahn, 2018; Wright, Hodges, Zimmer, \& McTigue, 2019). A related challenge over time for many students is that the academic writing system must coordinate with the listening, speaking, and reading systems, but each system is separate and may not develop at the same rate within individual students (Berninger \& Abbott, 2010).

As the articles in this section demonstrate, consensus is absent about the origins or developmental trajectories of the academic language registers (Christie \& Derewianka, 2008), much less the development of particular academic language features (see Fang \& Park, this issue). But, it is common knowledge that, when young children are learning how to employ first language oral systems and to coordinate their purposes, they also are learning the social registers of communication. Initially, young children acquire the conversational register associated with first language acquisition and face-to-face communication. The general features of this register are an interpersonal focus realized in turn-taking, high affective involvement, and online language production that occurs under real-time limitations with reduced linguistic complexity (Biber \& Conrad, 2003).

Only later during the preschool years, depending on the nature of preschool experiences, do the general beginnings emerge of a new way of communicating (van Kleeck, 2014). Common features of the academic language registers are a decreased interpersonal stance; less affective emphasis; increased objectivity of expression, which may need to be crafted for imaginary audiences; and, often, although not exclusively, an expository focus (Berman, 2014; Biber \& Conrad, 2003). More specifically, at the subword, word/multiword, phrase/syntactic, and discourse/text levels, writing-to-learn the academic language registers notably draws on "uncommonsense 
knowledge" (Christie \& Derewianka, 2008, p. 218), which expresses abstract concepts, judgments, and opinions that have reduced communicative dependence on the here and now. van Kleeck (2014) makes the case that academic language learning should begin in preschool. The argument is that, once children enter elementary school, academic language registers are rarely taught directly. The reason is mistakenly attributed to the belief that children know about the general academic language register (for a contrary view, see, Galloway, Qin, Uccelli, and Barr, this issue). Although the development of academic language - oral and written-continues throughout the school years and into young adulthood, students need directed instruction and many opportunities to practice in a variety of academic contexts to attain expertise.

\section{General and specialized academic language registers}

All students, including those with specific learning disabilities, are expected to acquire two intertwined aspects of the academic language register in both the oral and written domains. One facet is the general academic language register, which functions as the primary educational "gatekeeper" (Bailey, 2010, p. 229). Nagy and Townsend (2012) characterize this register as the facilitator of "communication and thinking about disciplinary content" (p. 92) in both oral and written areas.

This register presents a new kind of complexity to challenge students since interweaving the multiple levels of language into an integrated whole produces stretches of language that are "more or less "complex" (Ravid, Dromi, \& Kotler, 2010, p. 126; authors" quotation). This general register "consists of the overall linguistic and discourse tools necessary to manage reasoning, reading, and writing across disciplinary content areas" (Silliman \& Wilkinson, 2015, p. 293), such as knowing when, how, and where to alter multiple language levels to diversify intentions and meanings and interconnect topics, e.g., with connectives.

The specialized language sub-registers associated with the various disciplinary domains is the second development, building on the general language register starting with elementary experiences. Each academic language sub-register has varied amalgamations of linguistic and discourse features, from the word to discourse/textual levels, that may expand or decrease depending on the degree, scope, and quality of educational experiences (Zwiers, 2008). Nevertheless, three interconnected aspects generally characterize the specialized language of the sub-registers. One is textual connectivity of the theme (David \& Berman, 2014). A second facet is the generation of more complex linguistic content, which reduces redundancy (Ravid \& Berman, 2006; Ravid et al., 2010). The third feature emerges from the first two: enhanced conciseness and precision of expression (Snow, 2010), especially as constructed through the power of writing-to-learn (Berman, 2008). However, it is worth noting that the manner in which writing-to-learn specifically affects these outcomes remains unresolved (Silva \& Limongi, 2019).

To frame the five articles in this section, we draw on examples from the excerpt of the chemistry lab report written by the 15 -year-old high school student to show 
how the general and specialized registers flow from the overlapping, multileveled, and functional nature of the language system.

- Subword and word levels-These levels are intertwined in the writer's complexity building, which points to the rich lexical representations accessible from the writer's "chemistry lexicon." For example, from a subword perspective, all words in the excerpt (and in the report in general) are transcribed accurately, which suggests that the phonological, orthographic, and morphological components of spelling are unifying into automatic word forms.

- Word/multiword level-As just mentioned, the writer's lexical repertoire allows her to employ both general (albeit more literate) meanings (e.g., predicted, procedures, produces), disciplinary specific meanings (e.g., hydrogen, oxygen), and disciplinary specific derivations, both prefixes (single underline) and suffixes (double underlined) such as, [meta-acid] reaction, [water] displace $\underline{\underline{\text { rent }}}$.

- Phrase/syntactic (grammatical) level-The writer constructs informational density with two types of linguistic devices: elaborated noun phrases (ENPs) and dependent clauses. ENPs are embedded phrases that function to pack more information into a stretch of language (Biber \& Gray, 2016). They specify details related to noun, prepositional, or adjective phrases, contribute to increased length of expression, vary in the type of modification, and are consistent with scientific writing wherein ENPs generate complexity more often than do dependent clauses (Biber, Gray, \& Poopon, 2011). At the same time at the syntactic level, the writer produces a co-occurrence of different dependent clauses. Note in the last sentence that a multifaceted ENP is partially embedded in a relative clause (ENPs are italicized with more complex items italicized and bolded; dependent clause types are underlined):

- In this lab, I predicted [noun clause] that it [the hydrogen lab] would have similar results to the oxygen lab [adverbial clause] because the procedures were the same. The importance of this lab is for the students to be familiarized with meta-acid reaction [relative clause] that produces hydrogen gas, water displacement, and several properties of hydrogen gas.

- Discourse/text level-The writer introduces the theme and successively organizes and assembles it from the general to the specific through topic shifts, elaborations, and conclusions (the type of thematic unit is encased in a bracket).

- [Introduction] In this lab, I predicted that it (the hydrogen lab) would have similar results to the oxygen lab because the procedures were the same. [Elaboration] The importance of this lab is for the students to be familiarized with meta-acid reaction that produces hydrogen gas, water displacement, and several properties of hydrogen gas.

The continuous interplay among these multiple levels demonstrates that complexity is not a singular concept. Rather, as Biber and Gray (2016) outline, there are multiple kinds of complexity. Each differs "in important ways with respect to their structural and syntactic characteristics, their discourse functions, and their distribution across registers" (p. 246). The five articles in this special section capture the 
notion of diverse complexity of multiple language levels in their investigations of academic language registers. Of the five, three emphasize varying aspects of general academic language registers (Galloway, Qin, Uccelli and Barr; Truckenmiller and Petscher; Stuart, Connelly, and Dockrell) while the remaining two (Fang and Park; Bahr, Lebby, and Wilkinson) foreground specialized academic language registers. All of the studies offer well-considered educational recommendations to remedy the academic language writing gap.

\section{General academic language registers}

The cross-sectional study by Galloway, Qin, Uccelli, and Barr, part of a larger longitudinal investigation, examined the academic language features of expository writing, in this case through a reading comprehension measure and computer-assisted written summaries of science source texts on satellites or wind power. Participants consisted of a large urban sample in grades 4-7 ( $N=922$ students) located in the Eastern United States. A majority qualified for free/reduced price meals, indicating that most came from low-income families. Beginning with the premise that writing and reading are reciprocal processes, the study primarily focused on general academic language or what Galloway et al. referred to as cross-disciplinary or highutility academic language resources as represented by Core Academic Language Skills (CALS) that support both reading and writing. These authors define CALS as a comprehensive construct of multiple-levels of language (however, the study did not address the subword level). Results indicated that, irrespective of socio-demographic variables, what writers know about general academic language predicts the quality of their written science summaries relative to the lexical, syntactic, and discourse categories that served as the focus of analysis. Moreover, those students less adept with CALS were also less aware of the need to avoid first person pronouns when constructing summaries, and, instead, similar to the less-skilled students in the Fang and Park study, drew on a narrative writing strategy, which the authors interpreted as a more familiar writing strategy.

Truckenmiller and Petscher, reviewing evidence that supported multiple language levels as the foundational basis for both reading and writing, also designed a large-scale, cross-sectional study involving Florida students in grades $4(n=1316)$ and $8(n=1302)$. The purpose was to ascertain if the linguistic knowledge interrelating reading comprehension, general academic language, and word recognition also contributed to writing proficiency. General academic language knowledge was operationalized as deconstruction of word parts into a base word (word level; e.g., permission-permit), selection of a connective that best joined two sentences topically (syntactic/text level), and, although not explicitly stated, a word recognition task that addressed the subword level. For this task, students listened to a word and chose the correctly spelled real word or non-word from a list of three words. These measures were used to understand student performance on a writing task, the state writing assessment, which was a narrative composition for grade 4 and a persuasive essay for grade 8 . The written products were scored with a holistic scale. Results supported the shared knowledge perspective. General academic language, reading 
comprehension, and word recognition measures predicted a considerable amount of variance in the written composition pass rates. Students in grades 4 and 8 who demonstrated higher academic language skills were at lower risk for failing outcomes in written composition. Conversely, those with lower general academic language scores were at higher risk.

How children with oral language disorders manage aspects of the general academic register in text construction has rarely been explored. The inclusion of this group affords the opportunity to examine possible correlations between facets of oral language knowledge and written text development. To rectify this lapse, Stuart, Connelly and Dockrell chose to sample three linguistic stepping-stones to general academic writing: verb argument structures (such as transitive and intransitive structures that assist in completing meaning) and verb production (both accessing the phrase/syntactic level) and verb diversity (lexical level). Data were obtained from 90 students engaged in a narrative writing activity. All were approximately 10 years old and enrolled in British elementary classrooms. Students were administered standardized measures of oral sentence formulation and recall, reading fluency of single words, and spelling. They were assembled into three groups of 30 each: an experimental group diagnosed with a Developmental Language Disorder (DLD; $n=30$ ), a chronological age group (CA; $n=30)$, and a language ability group (LA; $n=30$ ) with the same raw scores as the DLD group on the oral language measure. Three sets of findings were pertinent. First, both the oral sentence formulation and reading fluency for single words, but not the spelling measure as assessed by spelling accuracy, were predictors of the numbers of written verbs and the number of different verbs produced, suggesting a level of bi-directionality or reciprocal relationship between these measures and certain stepping-stones. Second, significant differences did not emerge among the groups for the frequency of verb argument structures, a surprise finding, but, as expected, the frequency and diversity of verb production did differ with the CA group outperforming the DLD and LA groups; however, verb diversity was reduced in children with DLD compared to their CA matched peers. Third, findings indicated a pattern of instructional inadequacies in writing-to-learn. Although the requisite stepping-stones underlying this aspect of general academic language knowledge were underdeveloped for all three groups, the group with DLD more often tended to produce "lexical teddy bears" or the same verbs repeatedly. Stuart et al. voice the concern that a possible consequence for all students, but especially for those with DLD, is being left behind metaphorically on the riverbank, hanging onto their lexical teddy bears, and never reaching the other side to master disciplinary writing.

\section{Specialized academic language registers}

Fang and Park selected an informational text variation of expository writing obtained from 93 students in grades 7 and 9 attending Florida schools. The task was to write a science report about alligator habits. Student use of 11 academic language features and writing quality were subsequently analyzed, among other variables. The 11 features did not include the subword level (spelling) but did emphasize the word/ 
multiword, phrase/syntactic, and general text levels, the latter assessed in terms of overall writing quality. Although findings indicated within-grade variations in academic language features, there was no difference between the two grades. Patterns indicated that many students were struggling with the general and specialized academic language registers given that reports tended to be written in everyday conversational style. The authors partially attributed the absence of academic language features to the concern that contemporary instruction in language arts and other content areas fails to attend to the academic language registers with the possible exception of vocabulary. A speculation is that the dearth of attention to academic language also influences overall writing quality.

The Bahr, Lebby, and Wilkinson article addresses spelling, which is often erroneously regarded as a mechanical ability. However, as Bahr et al. underscore, spelling is the linguistic bridge for translating ideas into language. Moreover, English is a morphophonemic orthography because three linguistic codes, phonology (sound) and morphology (meaning) are progressively interrelated through the orthography. Bahr et al. attended to the subword level in the analysis of misspellings of 29 students in grades 5-9 (ages 11-14 years) in Pacific Northwest schools. All students had persistent specific learning disabilities (SLDs) (dysgraphia, dyslexia, or oral and written language learning disability, OWL LD, another term similar to developmental language disorders) as they engaged over six lessons in expository composing in a disciplinary academic register. Following extensive assessments, students were asked to take notes and handwrite or type summaries from source texts about world geography and cultures that they read or heard. This was important because minimal information exists about how transcription mode-handwriting or keyboarding — or how the manner of input of the source text (read or heard) during composing may affect the kinds of linguistic features that are misspelled by the different SLD diagnostic groups. The authors completed an analysis of the linguistic features associated with the 1778 words misspelled in the writing samples (of the 12, 622 words produced). Results indicated that students generated similar degrees of error complexity in their misspellings when writing in this specialized academic register regardless of the nature of their SLD, mode of presentation of source texts, or mode of transcription. Hence, individual variability and the complexity of the writing task, not diagnostic group, influenced spelling skill when composing in this academic register. Similar to findings from the Stuart et al. study, the complex architecture of written academic language expression remains a formidable challenge for a number of students with chronic SLD.

\section{Concluding remarks}

In summary, several cross cutting themes emerge from the five papers included in this special section. These are:

1. Fundamental challenges are inherent to the writing process within academic language registers, both general and specialized. This was noted across a broad range 
of students, from the typically developing to those with known and persisting weaknesses in language learning.

2. Relationships among the multiple levels of language knowledge are complex and are interwoven, evolving throughout schooling and even into the young adult years.

3. Students develop mastery of the general and specialized academic language registers over time and in concert with development of their disciplinary knowledge through the integration of reading with writing.

4. Beginning in the early elementary grades, teachers should create multiple activities to encourage students' engagement with multiple language levels and support different ways for students to generate linguistic/discourse complexity in the context of written academic registers.

5. Teachers must directly teach use of these registers.

Individually, each of the papers published here provides a significant contribution to our understanding of the relationships between academic language registers and literacy. Taken as a whole, the papers represent the state of inquiry in this area of educational research.

Finally, some implications for educational practice flow from the research presented in this special section. The primary implication is that students may benefit when their teachers, at all levels recognize that their role is to teach students how to write in the academic language registers while simultaneously teaching both the content and process of acquiring disciplinary knowledge. This change in instructional practice begins with teachers developing their own mastery of writing within the academic registers and understanding the significance of students mastering the process of writing-to-learn. Teachers need to assist students in learning how to understand and interpret disciplinary texts and discourse, including textbooks, word problems associated with classroom tasks, and standardized tests that require writing within the academic registers. Teachers may find it beneficial to familiarize themselves with the national standards and the language demands of high stakes assessments and centrally mandated textbooks and curricula-all of which require student mastery of the written academic registers.

Secondly, in terms of practice, teachers may find it useful to modify their instructional strategies so that students engage daily in meaningful writing of the academic language registers. This change includes providing learning opportunities that truly challenge students - so that they want to express what they know in writing within the academic registers. Students should work on disciplinary tasks, which may offer multiple opportunities to engage in the range of language forms utilized in the written disciplinary register. Writing-to-learn should offer opportunities to extend and offer greater precision than the oral register. Teachers need to teach academic writing to their students, if students are to attain mastery in this essential school competency.

A third step for teachers is to model the use of the academic language writing registers when they introduce, discuss, and present disciplinary knowledge and problem solving. Teachers' use of the academic writing registers in their own classrooms with students illustrates the complex and precise ways of expressing disciplinary 
ideas. Teachers have to both show and teach students how to accomplish building and communicating their disciplinary understandings through academic writing.

\section{References}

Abbott, R. D., Berninger, V. W., \& Fayol, M. (2010). Longitudinal relationships of levels of language in writing and between writing and reading in grades 1-7. Journal of Educational Psychology, 102, 281-298.

Bailey, A. L. (2010). Implications for assessment and instruction. In M. Shatz \& L. C. Wilkinson (Eds.), The education of English language learners: Research to practice (pp. 222-247). New York: Guilford Press.

Bar-Ilan, L., \& Berman, R. A. (2007). Developing register differentiation: The Latinate-Germanic divide in English. Linguistics, 45, 1-36. https://doi.org/10.1515/LING.2007.001.

Berman, R. A. (2007). Developing linguistic knowledge and use across adolescence. In E. Hoff \& M. Shatz (Eds.), Blackwell handbook of language development (pp. 347-367). Malden, MA: Blackwell.

Berman, R. A. (2008). The psycholinguistics of developing text construction. Journal of Child Language, 35, 735-771.

Berman, R. A. (2014). Linguistic perspectives on writing development. In B. Arfé, J. Dockrell, \& V. Berninger (Eds.), Writing development in children with hearing loss, dyslexia, or oral language problems (pp. 16-32). New York: Oxford University Press.

Berninger, V. W., \& Abbott, R. D. (2010). Listening comprehension, oral expression, reading comprehension, and written expression: Related yet unique language systems in grades 1, 3, 5, and 7. Journal of Educational Psychology, 102, 635-651.

Berninger, V. W., Richards, T., \& Abbott, R. D. (2015). Differential diagnosis of dysgraphia, dyslexia, and OWL LD: Behavioral and neuroimaging evidence. Reading and Writing: An Interdisciplinary Journal, 28, 1119-1153.

Biber, D. (2016). Using multi-dimensional analysis to explore cross-linguistic universals of register variation. In M. A. Lefer \& S. Vogeleer (Eds.), Genre and register related discourse features in contrast (pp. 7-34). Amsterdam: John Benjamins.

Biber, D., \& Conrad, S. (2003). Register variation: A corpus approach. In D. Schiffrin, D. Tannen, \& H. E. Hamilton (Eds.), The handbook of discourse analysis (pp. 175-196). Malden, MA: Blackwell Publishing.

Biber, D., \& Gray, B. (2016). Grammatical complexity in academic English: Linguistic change in writing. Cambridge: Cambridge University Press.

Biber, D., Gray, B., \& Poonpon, K. (2011). Should we use characteristics of conversation to measure grammatical complexity in L2 writing development? TESOL Quarterly, 45, 5-35.

Christie, F., \& Derewianka, B. (2008). School discourse. New York: Continuum International Publishing Group.

Cummins, J. (2014). Beyond language: Academic communication and student success. Linguistics and Education, 26, 145-154.

Davidi, O., \& Berman, R. A. (2014). Writing abilities of pre-adolescents with and without language/ learning impairment in restructuring an informative text. In B. Arfé, J. Dockrell, \& V. Berninger (Eds.), Writing development in children with hearing loss, dyslexia, or oral language problems (pp. 143-157). New York: Oxford University Press.

Dockrell, J. E., Marshall, C. R., \& Wyse, D. (2016). Teachers' reported practices for teaching writing in England. Reading and Writing, 29, 409-434. https://doi.org/10.1007/s11145-015-9605-9.

Fang, Z., Scheppegrell, M. J., \& Moore, J. (2014). The linguistic challenge of learning across academic disciplines. In C. A. Stone, E. R. Silliman, B. J. Ehren, \& G. P. Wallach (Eds.), Handbook of language and literacy: Development and disorders (2nd ed., pp. 302-322). New York: Guilford Press.

Graham, S. (2019). Changing how writing is taught. Review of Research in Education, 43, 277-303. https ://doi.org/10.3102/0091732X18821125.

James, K. H., Jao, R. J., \& Berninger, V. (2016). The development of multi-leveled writing brain systems; Brain lessons for writing instruction. In C. A. MacArthur, S. Graham, \& J. Fitzgerald (Eds.), Handbook of writing research (pp. 116-129). New York: Guilford Press. 
Nagy, W., \& Townsend, D. (2012). Words as tools: Learning academic vocabulary as language acquisition. Reading Research Quarterly, 47, 91-108. https://doi.org/10.1002/RRQ.011.

Nelson, K. L., \& Watkins, M. (2019). An examination of secondary English teachers' vocabulary instructional practices and the impact on them from professional development. Reading Improvement, 56, 118-133.

Neumann, S. (2016). Cross-linguistic register studies: Theoretical and methodological considerations. In M. A. Lefer \& S. Vogeleer (Eds.), Genre and register related discourse features in contrast (pp. 35-58). Amsterdam: John Benjamins.

Ravid, D., \& Berman, R. A. (2006). Information density in the development of spoken and written narratives in English and Hebrew. Discourse Processes, 41, 117-149.

Ravid, D., Dromi, E., \& Kotler, P. (2010). Linguistic complexity in school-age text production: Expository versus mathematical discourse. In M. A. Nippold \& C. M. Scott (Eds.), Expository discourse in children, adolescents, and adults (pp. 123-154). New York, NY: Psychology Press.

Silliman, E., \& Berninger, V. (2011). Cross-disciplinary dialogue about the nature of oral and written language problems in the context of developmental, academic, and phenotypic profiles. Topics in Language Disorders, 31, 6-23. Free access at http://journals.1ww.com/topicsinlanguagedisorders/ Fulltext/2011/01000/Cross_Disciplinary_Dialogue_about_the_Nature_of.3.aspx.

Silliman, E. R., \& Wilkinson, L. C. (2015). Two challenges of the academic language register for students with language learning disabilities. In R. H. Bahr \& E. R. SIlliman (Eds.), Routledge handbook of communication disorders (pp. 291-302). London: Routledge.

Silliman, E. R., Wilkinson, L. C., \& Brea-Spahn, M. (2018). Writing the science register and multiple levels of language. In A. L. Bailey, C. A. Maher, \& L. C. Wilkinson (Eds.), Language, literacy, and learning in the stem disciplines: How language counts for English learners (pp. 115-139). New York: Routledge.

Silva, A. M., \& Limongi, R. (2019). Writing to learn increases long-term memory consolidation: A mental-chronometry and computational modeling study of "epistemic writing". Journal of Writing Research, 11, 211-243.

Snow, C. E. (2010). Academic language and the challenge of reading for learning about science. Science, 328, 450-452. https://doi.org/10.1126/science.1182597.

U.S. Department of Education, Institute of Education Sciences, National Center for Education Statistics. (2011). National Assessment of Educational Progress (NAEP), writing at grades 8 and 12 (NCES 2012-470), Washington, DC.

van Kleeck, A. (2014). Distinguishing between casual talk and academic talk beginning in the preschool years: An important consideration for speech-language pathologists. American Journal of SpeechLanguage Pathology, 23, 721-724. https://doi.org/10.1044/2014_AJSLP-14-0032.

Wallis, P., Richards, T., Boord, P., Abbott, R., \& Berninger, V. (2017). Relationships between translation and transcription processes during fMRI connectivity scanning and coded translation and transcription in writing products after scanning in children with and without transcription disabilities. Creative Education, 8, 716-748. https://doi.org/10.4236/ce.2017.85055.

Wright, K. L., Hodges, T. S., Zimmer, W. K., \& McTigue, E. M. (2019). Writing-to-learn in secondary science classes: For whom is it effective? Reading and Writing Quarterly, 35, 289-304. https://doi. org/10.1080/10573569.2018.1541769.

Zwiers, J. (2008). Building academic language: Essential practices for content classrooms. Newark, DE: International Reading Association.

Zwiers, J., \& Crawford, M. (2011). Academic conversations: Classroom talk that fosters critical thinking and content understandings. Portsmouth, NH: Stenhouse Publishers.

Publisher's Note Springer Nature remains neutral with regard to jurisdictional claims in published maps and institutional affiliations. 